\title{
The use of GnRH analogs in preserving ovarian function during chemotherapy
}

\author{
Omar M. Odeh ${ }^{1}$, Johnny Awwad ${ }^{2}$, Dalia Khalife ${ }^{3}$ and Suleiman Ghunaim ${ }^{3 *}$
}

\begin{abstract}
Background: The literature has always been controversial on the use of gonadotropin-releasing hormone agonists in preserving fertility in women of childbearing age after chemotherapy; thereby, in this article, we will be discussing its use in preserving fertility.

Main body of abstract: When it comes to preserving fertility, it is crucial to consider all available options in this topic due to its very sensitive nature, thereby we have found that while a lot of trials favor the use of gonadotropin-releasing hormone agonists, the lack of proper follow-up and long-term trials renders its use highly debatable, and since the longest follow-up trial showed non-significant results, it also opens the floor for debate on whether this shortterm benefit is worth adding another drug to the regimen or not.
\end{abstract}

Short conclusion: As described in this review, while the use of gonadotropin-releasing hormone agonists is beneficial in a lot of studies, the lack of long-term reports still makes its use debatable, thereby more trials should be done.

Keywords: GnRH agonists, Fertility, Chemotherapy

\section{Background}

The management of malignancy in women in their reproductive years may necessitate a surgical, radiological, or a cytotoxic (chemotherapy) approach which exposes the female to dangerous and even toxic doses that will ultimately result in gonadal damage and dysfunction.

Prior to initiating potentially gonadotoxic therapy, physicians should discuss the risk of treatment-induced infertility and possible interventions to preserve fertility [1]. This discussion should occur soon after diagnosis since some interventions to preserve fertility take time and could delay the start of treatment. The ASCO's (American Society of Clinical Oncology) committee opinion stated in 2006 and reaffirmed in 2013 that as part of education and informed consent before cancer therapy, healthcare providers (including medical oncologists,

\footnotetext{
*Correspondence: suleimanghunaim@gmail.com

3 Department of Obstetrics and Gynecology, Division of Reproductive Endocrinology and Infertility, Haifa Idriss-ART Unit, American University of Beirut, Beirut, Lebanon

Full list of author information is available at the end of the article
}

radiation oncologists, gynecologic oncologists, urologists, hematologists, pediatric oncologists, and surgeons) should address the possibility of infertility with patients treated during their reproductive years (or with parents or guardians of children) and be prepared to discuss fertility preservation options and/or to refer all potential patients to appropriate reproductive specialists. The ASCO's committee also stated in 2018 that the guidelines emphasize the use of measures to preserve fertility in young women with cancer, and such measures include assisted reproductive techniques and ovarian protection through the use of GnRH agonists. Although patients may be focused initially on their cancer diagnosis, it is encouraged to advise patients regarding potential threats to fertility as early as possible in the treatment process so as to allow for the widest array of options for fertility preservation [2].

This emphasizes the importance of a multidisciplinary approach and collaborative work between oncologists and reproductive medicine specialists in tackling such a crucial and sensitive issue. 
In general, the ovaries of women who receive chemotherapy have a decreased number of primordial follicles which will result even in a greater decrease in the numbers of larger maturing follicles indicating a greater chemotherapeutic effect on follicular development rather than on the oocyte itself. Many young women develop amenorrhea during chemotherapy, and this is what is called chemotherapy-induced amenorrhea which on its own has a significant independent clinical impact (type and dose-dependent) on survival [3]. Reviewing the results of the International Breast Cancer Study Group (IBCSG) Trial VI showed that adjuvant chemotherapyinduced amenorrhea has been shown to be associated with reduced relapses and improved disease-free and overall survival for premenopausal breast cancer patients and is especially significant for node-positive breast cancer [4].

In general, women younger than age 40 years are more likely to retain their menstrual cycles than those older than 40 as they have a larger pool of follicles [5].

Multiple approaches are available for fertility preservation in women undergoing gonadotoxic treatment, these include the following:

1- Cryopreservation of embryos

2- Cryopreservation of mature and immature oocytes

3- Cryopreservation of ovarian tissue

4- Ovarian transposition

5- Gonadal shielding during radiation therapy

6- The use of GnRH analogs in patients with chemotherapy

The efficacy of the use of the GnRH analogs for preserving ovarian function during chemotherapy was always debated in the literature with different findings across multiple randomized controlled trials, with some data regarded as heterogeneous due to the fact that there was no uniform or an absolute definition for premature ovarian failure with many studies referring to amenorrhea as a reflector of ovarian function as well as the scarcity of data on future patient fertility, pregnancy, as well as pregnancy outcomes.

In this review, we will be tackling the issue of the use of the GnRH analogs in preserving ovarian function in patients receiving chemotherapy.

\section{Main text}

\section{Biology of GnRH analogs}

In 1977, the structure of the GnRH was properly identified by Drs. Guillemin and Schally [6]. A decapeptide (pyro Glu-His-Trp-Ser-Tyr-Gly-Leu-Arg-Pro-Gly- $\mathrm{NH}_{2}$ ) synthesized from a 92-amino acid preprohormone in the preoptic nucleus in the hypothalamus. The portal blood carries the GnRH to the pituitary gland, which contains the gonadotrope cells, where GnRH activates its own receptor, gonadotropin-releasing hormone receptor (GnRHR), to release FSH and LH.

The half-life of GnRH is $2-4$ min as it is degraded by peptidase and cleared by glomerular filtration [7], and this was probably the main reason for developing longeracting agonistic derivatives to increase their duration of action [8]. The GnRH analog causes an initial flare effect that increases gonadotropin levels and causes ovarian stimulation followed by a hypogonadotrophic state within 1-3 weeks of administration [7].

The administration of LHRHa is associated with some adverse effects (e.g., headache, hot flashes, vaginal dryness, sweating, mood changes, insomnia, urogenital symptoms, and thromboembolic events).

Safety concerns regarding its use were raised suggesting a possible increase in the side effects during cytotoxic therapy, a possible detrimental effect of the lack of treatment-induced amenorrhea on prognosis, and a potential negative interaction with chemotherapy.

However, the three available randomized studies [911] that investigated the impact of adding concurrent ovarian function suppression to chemotherapy did not demonstrate any difference in patients' prognosis.

\section{Mechanism of action in fertility preservation}

In the adult ovary, $>90 \%$ of the ovarian reserve is made up of primordial follicles in the resting stage prophase I. Growth initiation of follicles is initially an FSH-independent process and gonadotropin-dependent growth would not occur until later on (antral phase) [12]. Because profound ovarian suppression may take several weeks to achieve, it is unlikely that sufficient lowering of gonadotropins will be achieved within the short time available before the initiation of chemotherapy. Also, if $\mathrm{GnRH}$ analogs are given during the follicular phase of the cycle, they may actually cause a flare effect and create the opposite of the desired impact and defeat the purpose of actually suppressing ovarian function during chemotherapy treatment.

This raised many questions regarding how GnRH analogs actually work in fertility preservation.

A proposed intervention in mice showed that gonadotropins enhance caspase- 3 and caspase- 7 and apoptosis in the theca-interstitial cells of rat preovulatory follicles in culture. The elevations in caspase- 3 and caspase-7 activities in theca-interstitial cells were accompanied by an increase in apoptosis [13], since theca-interstitial cells are important for follicle development, this increase in apoptosis might explain the preservation of preovulatory follicles, as this can help them maintain a relatively dormant state. Thus, pituitary desensitization, 
induced by $\mathrm{GnRH}$ agonist administration, prevents the secretion of growth factors by the FSH-dependent follicles, thus secondarily preserving more primordial follicles in the "dormant" stage and minimizing their unidirectional maturation and ultimate destruction by alkylating agents

Two recent publications found that the proliferation of primordial germ cells is gonadotropin-dependent and is mediated by Akt/phosphatase and tensin homolog deleted on chromosome ten (PTEN) signaling. High concentrations of estrogens stimulate mouse primordial germ cell growth in vitro. Moreover, estrogens stimulate the transcription of the "Steel" gene and the production of c-Kit ligand in gonadal somatic cells, and this growth factor is likely to be responsible for the observed stimulation of primordial germ cell growth via an Akt/PTEN pathway $[14,15]$. Although the initiation of primordial follicle growth and the early stages of folliculogenesis can occur without gonadotropins, FSH may affect the rate of preantral follicle growth as well; therefore, the assumption that early follicles are gonadotropin independent may need re-evaluation [15-18].

Another proposed modality of action aims to decrease the utero ovarian perfusion created by high estrogen states in the body. High estrogen concentrations significantly increased ovarian perfusion and vessel endothelial area in a rat model of ovarian hyperstimulation, and this effect was significantly and dosedependently inhibited by administration of a GnRH agonist.

Moreover, it has been shown that human gonads contain independent GnRH receptors. GnRH-I and GnRH-II receptor activation may result in decreased apoptosis. Whether the GnRH agonist effect is direct on the oocyte-cumulus complex or on the granulosa cells themselves, this topic in particular requires further assessment [19].

Another possibility is that GnRH agonists may upregulate an intragonadal antiapoptotic molecule such as sphingosine-1-phosphate (S1P). Tilly et al. [20] have identified several molecules that are required for chemotherapy-induced oocyte apoptosis. While much of their work has relied on mice genes, they have identified a lipid antagonist of the proapoptotic second messenger ceramide, S1P, as a protective molecule [21].

\section{Clinical data}

In this review, we will be discussing the use of GnRH analogs in patients with breast cancer and hematological malignancies, since breast cancer is the most common cancer in women, and due to lack of available data, only hematological malignancies were discussed.

\section{Breast cancer}

Del Maestro et al. [22] demonstrated that the use of triptorelin-induced temporary ovarian suppression during chemotherapy in premenopausal patients with early-stage breast cancer reduced the occurrence of chemotherapyinduced early menopause. The study group looked at the incidence of early menopause in young (aged 18-45) patients with breast cancer undergoing adjuvant or neoadjuvant chemotherapy in a randomized controlled trial in 16 sites in Italy where patients were randomized into receiving chemotherapy alone vs chemotherapy and triptorelin administered intramuscularly at a dose of $3.75 \mathrm{mg}$ at least 1 week before the start of chemotherapy and then every 4 weeks for the duration of chemotherapy. Early menopause was defined as no resumption of menstrual activity and postmenopausal levels of FSH and estradiol 1 year after the last cycle of chemotherapy. The study included hormone receptor-positive as well as hormone receptor-negative breast cancer patients where hormone receptor-positive patients received adjuvant treatment with tamoxifen for up to 5 years. There was no significant difference between the chemotherapy regimens their patients received, either CMF-based (cyclophosphamide, methotrexate, and fluorouracil), anthracycline-based, or anthracycline-taxane-based treatment. With 133 patients randomized to chemotherapy alone and 148 patients randomized to chemotherapy plus triptorelin, the rate of early menopause was $25.9 \%$ in the chemotherapy-alone group and $8.9 \%$ in the chemotherapy plus triptorelin group $(P=0.001)$ thus an attributable risk reduction of $17 \%$ (95\% confidence interval, $-26 \%$ to $-7.9 \%$; $P<.001$ ). In a multivariate analysis, only the treatment with triptorelin was associated with a significant reduction of the risk of developing early menopause with an odds ratio for treatment-related early menopause of 0.28 (95\% confidence interval, 0.14 to $0.59 ; P<.001$ ).

Moore et al. [23] demonstrated in a phase 3 trial that ovarian failure rate was significantly less in patients receiving goserelin starting 1 week before the start of the chemotherapy regimen than those in the control group (odds ratio, 0.30; 95\% confidence interval [CI], 0.09 to 0.97; $P=0.04$ ). Furthermore, after a 5 -year follow-up, they also showed that those who received goserelin were more likely to get pregnant than the control group (odds ratio, $2.45 ; 95 \% \mathrm{CI}, 1.09$ to $5.51 ; P=0.03$ ), without the presence of a difference in pregnancy complications.

In 2012, Munster et al. [24] looked at premenopausal women aged 44 years or younger which were randomly assigned to receive either triptorelin or no triptorelin during neoadjuvant chemotherapy and assessed the preservation of their ovarian function through and after receiving chemotherapy. These patients were stratified by age ( $<35,35$ to $39,>39$ years), estrogen receptor status, 
and chemotherapy regimen. Premature ovarian failure was defined based on a resumption of menses and serial monitoring of follicle-stimulating hormone (FSH) and inhibin A and B levels. The study targeted 124 patients with a planned 5-year follow-up; however, the trial was stopped for futility after 49 patients were enrolled (median age, 39 years; range, 21 to 43 years); 47 patients were treated according to assigned groups with four cycles of adriamycin plus cyclophosphamide alone or followed by four cycles of paclitaxel or six cycles of fluorouracil, epirubicin, and cyclophosphamide. Menstruation resumed in $19(90 \%)$ of 21 patients in the control group and in $23(88 \%)$ of 26 in the triptorelin group $(P=.36)$. Menses returned after a median of 5.8 months (range, 1 to 19 months) after the completion of chemotherapy in the triptorelin vs 5.0 months (range, 0 to 28 months) in the control arm $(P=.58)$. Two patients (age 26 and 35 years at random assignment) in the control group had spontaneous pregnancies with term deliveries. FSH and inhibin B levels correlated with menstrual status. The study demonstrated that after patient stratification for age, estrogen receptor status, and treatment regimen, amenorrhea rates on triptorelin were comparable to those seen in the control group (10\% vs $12 \%$ hazard ratio of 0.76 ( $95 \% \mathrm{CI}, 0.40$ to 1.46 ) indicating no statistically significant advantage of adding triptorelin).

In a randomized, parallel-group study, the Anglo Celtic Group OPTION trial by Leonard et al. [25] which recruited 227 patients, goserelin reduced the prevalence of amenorrhoea between 12 and 24 months to $22 \%$ vs $38 \%$ in the control group $(P=0.015)$ and the prevalence of POI to $18.5 \%$ vs $34.8 \%$ in the control group $(P=0.048)$. Follicle-stimulating hormone concentrations were also lower in all women treated with goserelin at both 12 and 24 months $(P=0.027, P=0.001$, respectively). However, the use in women above the age of 40 proved to be nonsignificant, further strengthening the evidence supporting the use of GnRHa, but that still does not deny the fact that longer-term outcomes are yet to be studied and that the efficacy in preserving ovarian function is still limited.

A meta-analysis on 14 RCTs [26] showed that the use of $\mathrm{GnRHa}$ is favorable as it significantly reduced the risk of POF when given during chemotherapy (OR 0.36, $95 \%$ CI $0.23-0.57, P<0.001)$. Only 5 studies out of the 14 RCTs studied post-chemotherapy pregnancies, which was also deemed significant (OR 1.83, 95\% CI 1.02-3.28, $P=0.041)$. This calls for more trials to study the pregnancy rates after chemotherapy, as the current literature does not have much information on this specific variable.

Another meta-analysis done by Lambertini et al. [27] on 5 trials supported the use of GnRHa, but an interesting fact is that they also stated that a younger age $(<40$ years) at diagnosis was a significant variable (adjusted
OR, 0.35; 95\% CI, 0.24-0.52; $P<0.001$ ) when it came to the reduction of risk of developing chemotherapyinduced premature ovarian insufficiency (POI), thereby concluding that age is a major variable when it comes to the success of the use of GnRHa in the prevention of chemotherapy-induced POI.

One of the trials supporting the use of triptorelin, the PROMISE trial [28], specifically when it comes to the long term, which is one of the points that makes the use of GnRH agonists debatable, but it is worth mentioning that they also concluded that it does not affect pregnancy rates. The variable found significant was menstrual resumption at 5 years between the GnRHa and control group, 1.28 (95\% CI, 0.98-1.68; $P=0.07$ ) (Table 1).

\section{Hematological malignancies}

Salama et al. [29] in a review addressed preserving fertility in female patients with hematological malignancies, in which they have discussed the use of GnRH agonist along with a lot of other methods. Given that they have stated that the use of $\mathrm{GnRH}$ agonists is debatable, it is worth noting that they have stated that it is not suitable for use in prepubertal females due to inactive HPO axis, does not require a delay in cancer treatment, should be carried out before and during chemotherapy, and that it does not protect against the gonadotoxic effects of radiotherapy. However, it was listed as debatable due to contradictory results.

In another retrospective cohort study, triptorelin (Decapeptyl) was administered monthly to 61 women with Hodgkin lymphoma who were under treatment from 1994 to 2006. And out of these 61 women, 50 recovered regular menses, and after the completion of treatment, 13 patients conceived successfully. Falorio et al. [30] concluded that the use of GnRHa may be useful in preventing ovarian damage and infertility in young women receiving polychemotherapy alone or in combination with subdiaphragmatic radiotherapy, but it is not effective in refractory or relapsed patients, since they have found a clear correlation between age at the time of treatment, advanced disease, cumulative therapeutic load, and ovarian failure.

Another study including data from more than 20 years ago was carried out by Driul et al. [31], where they aimed to assess ovarian function in those receiving GnRHa compared to those who did not in a case-control study in survivors of hematological malignancies, where they analyzed 124 patients between 1998 and 2007. The results showed that in those treated with GnRHa, 33\% had post-treatment amenorrhea and 6\% post-treatment pregnancies, compared to $49 \%$ and $4 \%$, respectively, in the control group; however, they have 


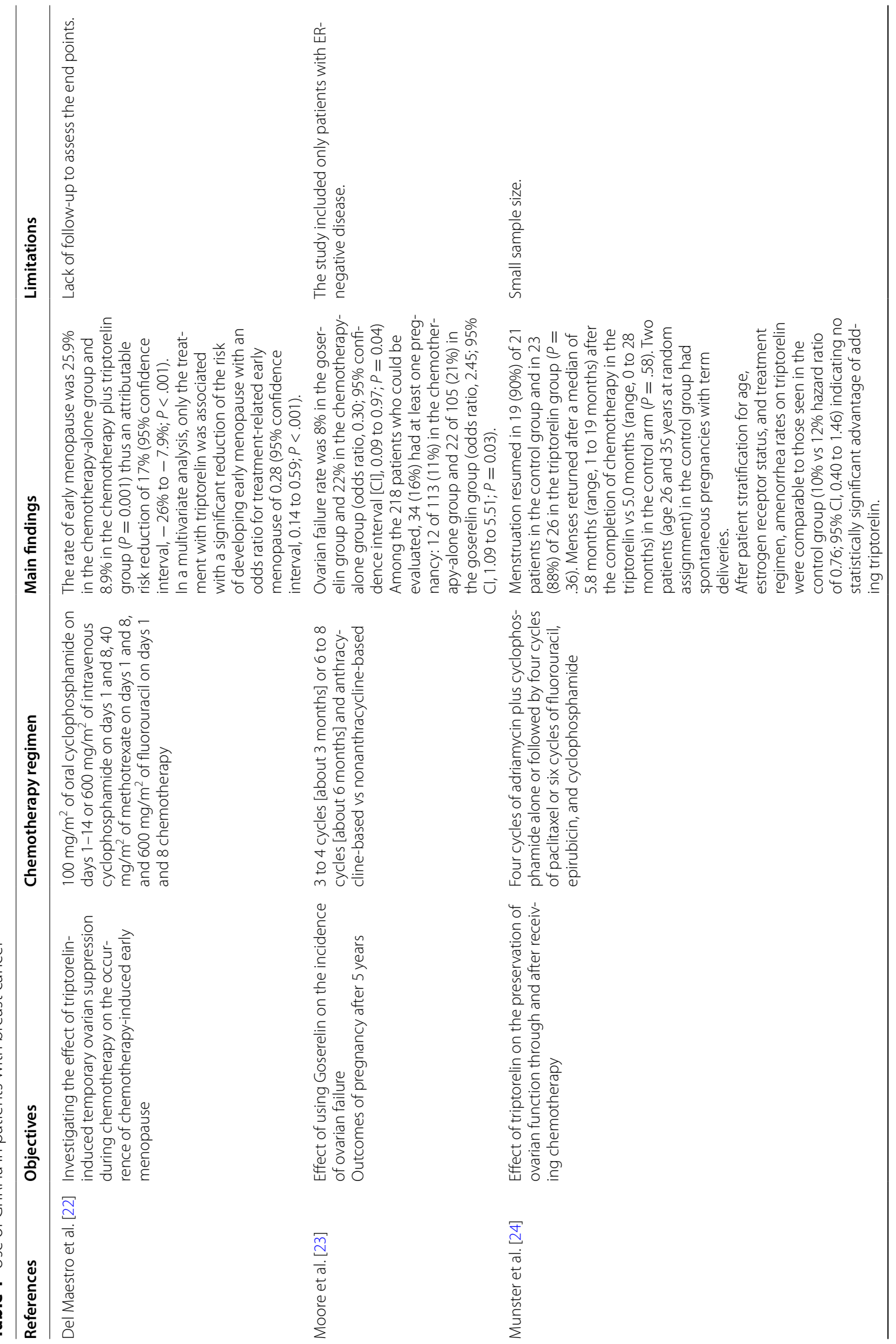




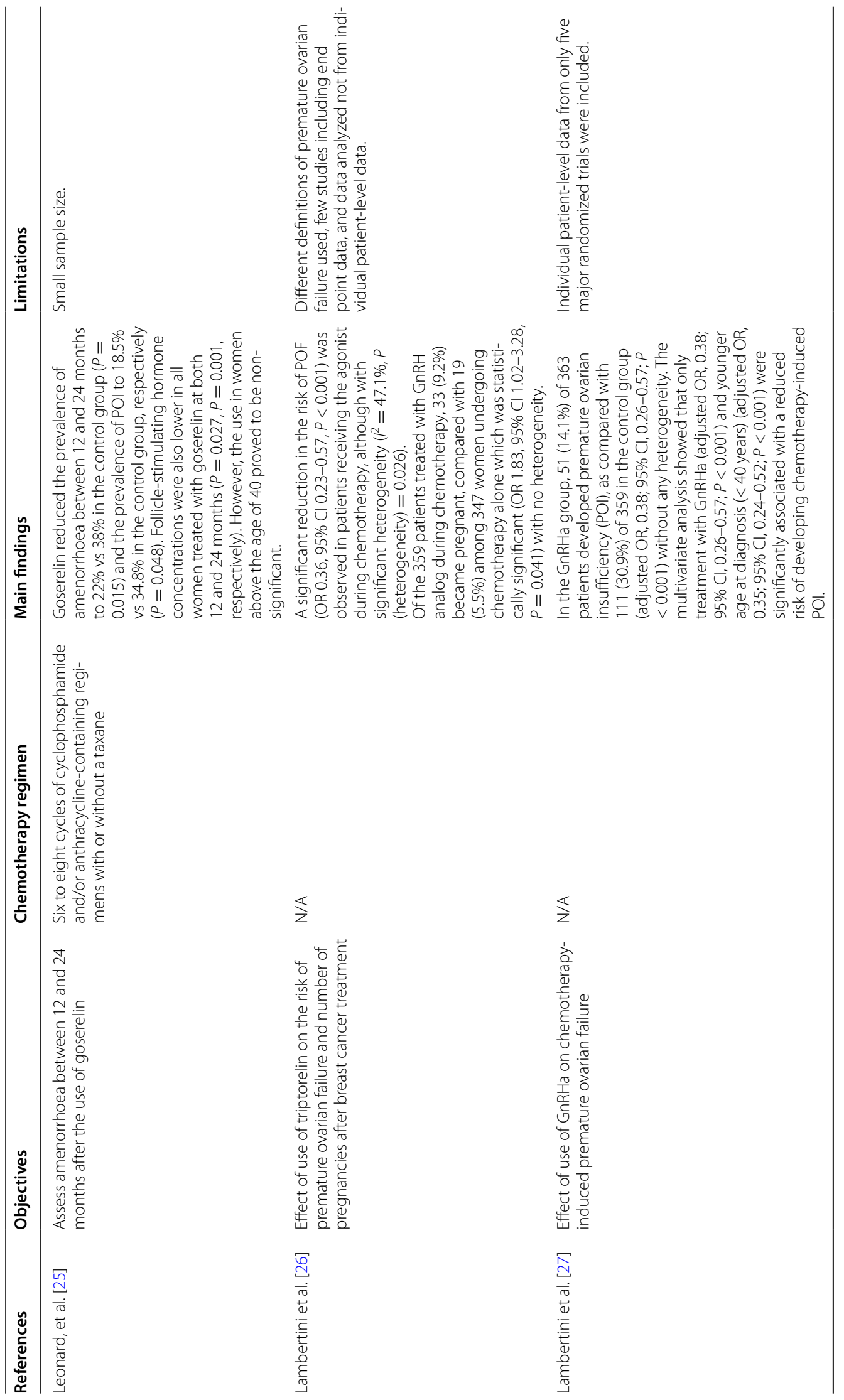




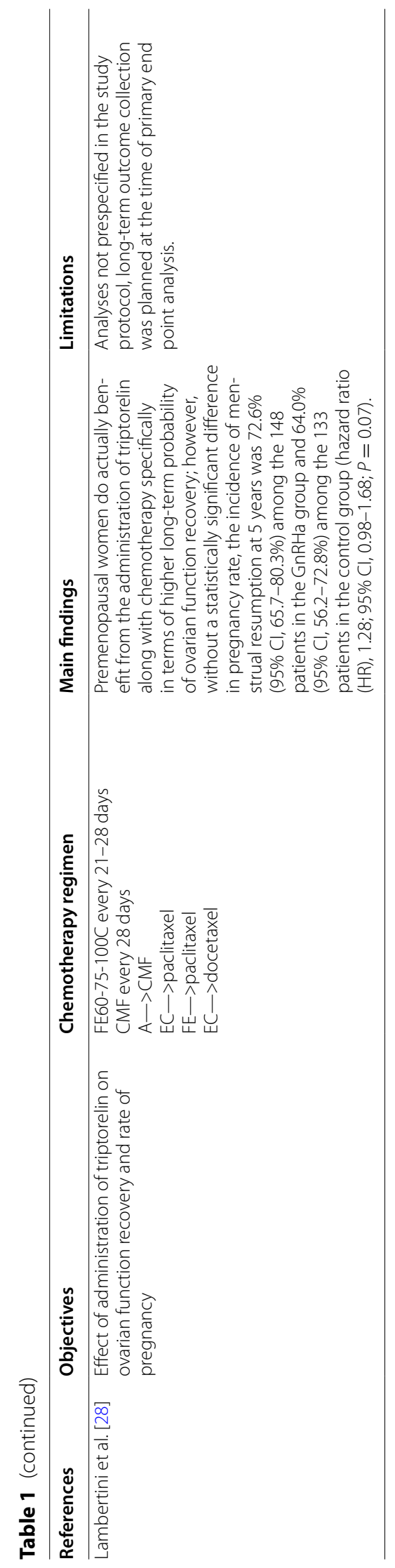


concluded that there was no statistical significance to emphasize on the use of GnRHa and that more evidence should be obtained.

A retrospective cohort study compared 286 patients who received GnRH agonist with chemotherapy and 188 patients who were treated with chemotherapy alone, and in this study, the primary outcome was spontaneous pregnancies. The secondary outcome was cyclic ovarian function (COF) vs premature ovarian failure (POF). These outcomes were assessed 2 years or more after chemotherapy. Blumenfeld et al. [32] concluded that spontaneous conception is significantly achieved in the intervention group $(P=.0004$, OR $3.12,95 \%$ CI 1.7-5.8), and adding to that preservation $\operatorname{COF}(P=.0001)$, thereby adding to the literature in supporting the use of GnRHa. Furthermore, 123 healthy newborns were born in the intervention group, compared to 40 in the control group.

In a prospective non-randomized case-control study, Blumenfeld et al. [33] elaborated on the effect of co-treatment with GnRHa on ovarian damage and concluded that it may reduce ovarian damage significantly. This study recruited 115 female patients with Hodgkin lymphoma, where 65 patients received a monthly injection of $\mathrm{GnRHa}$ throughout and before starting chemotherapy, up to a maximum of 6 months. The results showed that the resumption of regular menses was significantly seen in the intervention group; however, no significance was seen on the preservation of $\mathrm{COF}$, which contradicts previous studies, and these results further emphasize the need for more trials on the use of GnRHa.

Taking it a step further, in a study aiming to compare the rate of POF after stem cell transplantation (SCT) in women receiving $\mathrm{GnRHa}$ in conjunction with gonadotoxic chemotherapy, Blumenfeld et al. [34] showed that in 83 patients, 18 out of the 47 patients receiving GnRHa resumed cyclic ovarian function, compared with 4 out of the 36 not receiving GnRHa. There were no significant differences in age, chemotherapy treatment, or diagnoses between the study and control groups. They concluded that GnRHa cotreatment in conjunction with conditioning chemotherapy before SCT may significantly decrease the gonadotoxicity and POF from 82 to $33 \%$ in lymphoma but not in leukemia patients.

On the other hand, Demeestere et al. [35] showed that even though on the short term, the ovarian function might be better in a group receiving GnRHa when compared to a control group $(3.14 \pm 0.80 \mathrm{ng} / \mathrm{mL}$ at inclusion vs $1.26 \pm 0.3 \mathrm{ng} / \mathrm{mL}$ after 2 to 4 years, $P=.039$ ); this significance was no longer seen when it came to a longterm follow-up $(1.58 \pm 0.38 \mathrm{ng} / \mathrm{mL}, P=.520)$. In their study, they signified the fact that more trials should be done to assess the long-term effects of the use of $\mathrm{GnRHa}$ in preserving fertility, and this calls for the discussion of whether this short-term improvement is worth the addition of GnRHa or not (Table 2).

\section{Conclusions}

As described in this RCT review, the issue of GnRH analogs is still highly debatable in the literature with conflicting evidence and heterogeneous data.

The reason behind the heterogeneity of data may arise from the lack of a consistent uniform definition of premature ovarian failure following chemotherapy, with a clear focus on the resumption of menses as a primary indicator of resumed ovarian function. Focus on pregnancy outcomes as well as survival rates were never the primary outcomes in any of the studies which looked at the role of the use of $\mathrm{GnRH}$ analogs in ovarian function preservation. In the above most recent meta-analysis [24], there was an inclusion of RCTs with small patient populations that may not reflect back properly on the general population and may not be strong enough to influence any change in recent guidelines and consensus about using $\mathrm{GnRH}$ analogs in young patients receiving chemotherapy.

The administration of GnRH analogs in patients receiving chemotherapy offers a more accessible option for patients and can be used in conjunction with traditional fertility preservation techniques; it also offers feasibility in regard to cost, timing issues, and the need for a partner.

The American Society of Clinical Oncology Clinical Practice Guidelines (2013) regard sperm and embryo cryopreservation as well as oocyte cryopreservation as standard practice with other fertility preservation methods, including the use of GnRH analogs, considered investigational and should be performed by providers with the necessary expertise. Yet, in 2015, the St. Gallen International Expert Consensus panel and the National Comprehensive Cancer Network (NCCN) guidelines have been updated to acknowledge the role of luteinizing hormone-releasing hormone agonists (LHRHa) in preventing chemotherapy-induced POF of hormone receptor-negative breast cancer.

Moreover, in hormone receptor-positive breast cancer patients, the issue of the concurrent use of endocrine therapy, namely tamoxifen along with chemotherapy has demonstrated to be of inferiority in regard to disease-free survival when compared to a sequential administration [30] due to potential antagonism between tamoxifen and the cytotoxic agent. Yet, recently reported excellent survival results with triptorelin administered concurrently with chemotherapy in the Tamoxifen and Exemestane Trial [36] suggests that the use of GnRH agonist may also have a role in improving survival. This overall reflects a hesitant opinion to recommend this technique. 


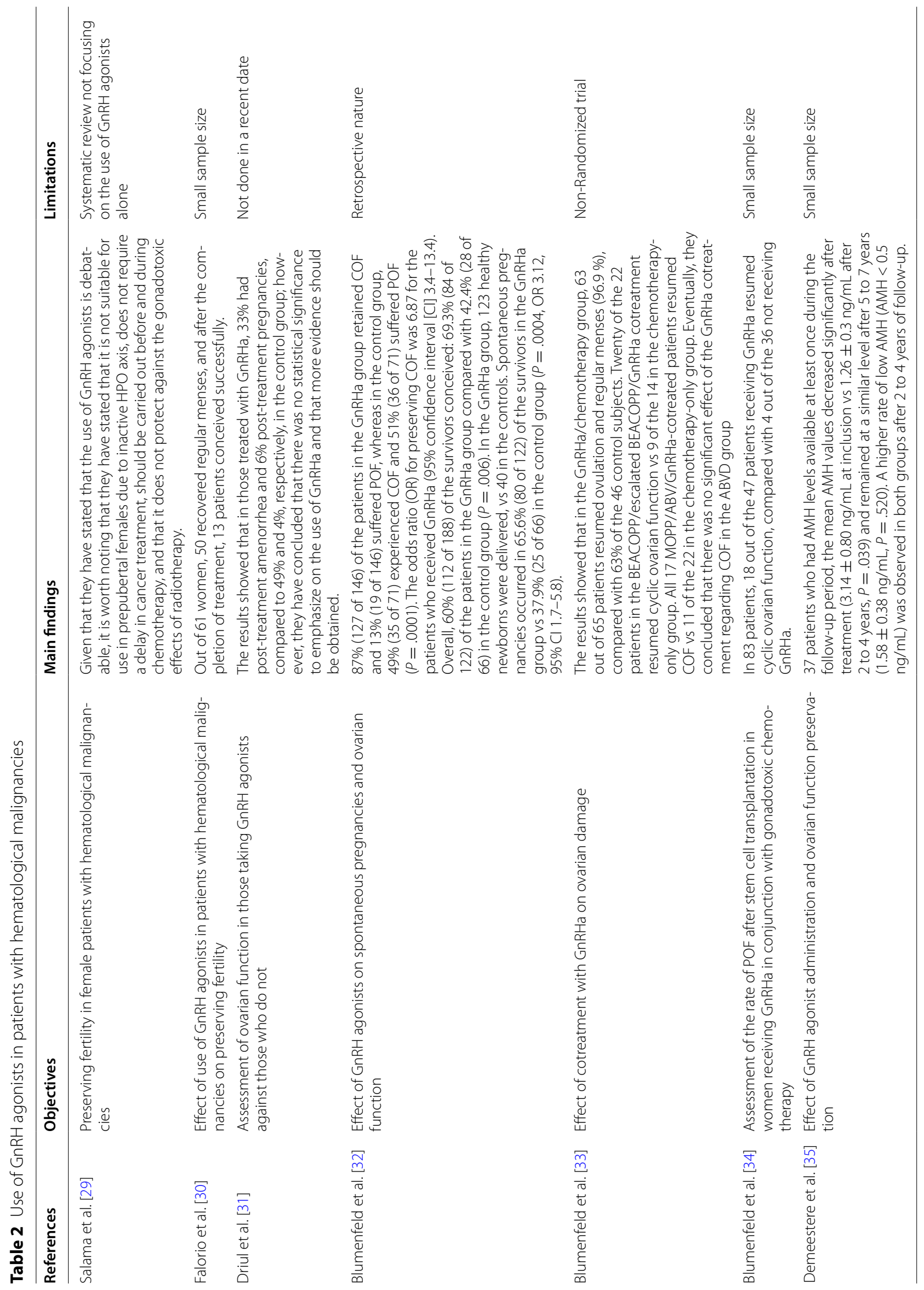




\section{Abbreviations}

GnRHa: Gonadotropin-releasing hormone agonist/analog; COF: Cycling ovarian function; POF: Premature ovarian failure; LHRHa: Luteinizing hormonereleasing hormone analog; POI: Premature ovarian Insufficiency.

\section{Acknowledgements}

Not applicable.

\section{Authors' contributions}

S.G, the corresponding author, ensured that the entire group is fully aware of the best practices in the discipline of publication and the full author list and order. O.O finalized the manuscript; in addition to that, all authors have read and approved the final manuscript, contributed substantially in the drafting and revision of the review. Furthermore, all authors have agreed to be personally accountable for the author's own contributions and that questions related to the accuracy or integrity of any part of the work are appropriately investigated, resolved, and the resolution documented in the literature.

\section{Funding}

Not applicable.

\section{Availability of data and materials}

Not applicable.

\section{Declarations}

\section{Ethics approval and consent to participate}

Not applicable

\section{Consent for publication}

Not applicable

\section{Competing interests}

The authors declare that they have no competing interests.

\section{Author details}

${ }^{1}$ School of Medicine, The University of Jordan, Amman, Jordan. ${ }^{2}$ Department of Obstetrics and Gynecology, Faculty of Medicine, American University of Beirut, PO Box 11-236, Riad El-Solh, Beirut 1107 2020, Lebanon. ${ }^{3}$ Department of Obstetrics and Gynecology, Division of Reproductive Endocrinology and Infertility, Haifa Idriss-ART Unit, American University of Beirut, Beirut, Lebanon.

Received: 18 June 2021 Accepted: 20 October 2021

Published online: 01 November 2021

\section{References}

1. Logan S, Perz J, Ussher J, Peate M, Anazodo A (2017) Clinician provision of oncofertility support in cancer patients of a reproductive age: a systematic review. Psycho-Oncology 27(3):748-756. https://doi.org/10.1002/ pon. 4518

2. (2018) Fertility preservation and reproduction in patients facing gonadotoxic therapies: an Ethics Committee opinion. Fertil Steril 110(3):380-386. https://doi.org/10.1016/j.fertnstert.2018.05.034

3. Warne GL, Fairley KF, Hobbs JB, Martin FI (1973) Cyclophosphamideinduced ovarian failure. New Engl J Med 289(22):1159-1162. https://doi. org/10.1056/nejm197311292892202

4. Pagani O, O'Neill A, Castiglione M, Gelber R, Goldhirsch A, Rudenstam C et al (1998) Prognostic impact of amenorrhoea after adjuvant chemotherapy in premenopausal breast cancer patients with axillary node involvement: results of the International Breast Cancer Study Group (IBCSG) trial VI. Eur J Cancer 34(5):632-640. https://doi.org/10.1016/s09598049(97)10036-3

5. Nicosia SV, Matus-Ridley M, Meadows AT (1985) Gonadal effects of cancer therapy in girls. Cancer 55(10):2364-2372. https://doi.org/10.1002/10970142(19850515)55:103.0.co:2-e
6. Kochman K (2012) Evolution of gonadotropin-releasing hormone $(\mathrm{GnRH})$ structure and its receptor. J Anim Feed Sci 21, 3(1):-30. https://doi.org/10. 22358/jafs/66031/2012

7. Fritz, M. A., \& Speroff, L. (2011). Clinical gynecologic endocrinology and infertility (8th ed.). Philadelphia: Wolters Kluwer Health/Lippincott Williams \& Wilkins

8. Kumar P, Sharma A (2014) Gonadotropin-releasing hormone analogs: understanding advantages and limitations. J Human Reprod Sci 7(3):170. https://doi.org/10.4103/0974-1208.142476

9. Original article (1990) Late effects of adjuvant oophorectomy and chemotherapy upon premenopausal breast cancer patients. Ann Oncol 1(1):30-35. https://doi.org/10.1093/oxfordjournals.annonc.a057670

10. Rivkin SE, Green S, Osullivan J, Cruz AB, Abeloff MD, Jewell WR et al (1996) Adjuvant CMFVP versus adjuvant CMFVP plus ovariectomy for premenopausal, node-positive, and estrogen receptor-positive breast cancer patients: a Southwest Oncology Group study. J Clin Oncol 14(1):46-51. https://doi.org/10.1200/jco.1996.14.1.46

11. Arriagada R, Lê MG, Spielmann M, Mauriac L, Bonneterre J, Namer M et al (2005) Randomized trial of adjuvant ovarian suppression in 926 premenopausal patients with early breast cancer treated with adjuvant chemotherapy. Ann Oncol 16(3):389-396. https://doi.org/10.1093/ annonc/mdi085

12. Oktay K (1997) Ontogeny of follicle-stimulating hormone receptor gene expression in isolated human ovarian follicles. J Clin Endocrinol Metab 82(11):3748-3751. https://doi.org/10.1210/jc.82.11.3748

13. Yacobi K, Wojtowicz A, Tsafriri A, Gross A (2004) Gonadotropins enhance caspase-3 and -7 activity and apoptosis in the theca-interstitial cells of rat preovulatory follicles in culture. Endocrinology 145(4):1943-1951. https:// doi.org/10.1210/en.2003-1395

14. Lacham-Kaplan $O$ (2004) In vivo and in vitro differentiation of male germ cells in the mouse. Reproduction 128(2):147-152. https://doi.org/10. 1530/rep.1.00220

15. Moe-Behrens GH, Klinger FG, Eskild W, Grotmol T, Haugen TB, Felici MD (2003) Akt/PTEN signaling mediates estrogen-dependent proliferation of primordial germ cells in vitro. Mole Endocrinol 17(12):2630-2638. https:// doi.org/10.1210/me.2003-0006

16. Zheng W, Magid MS, Kramer EE et al (1996) Follicle-stimulating hormone receptor is expressed in human ovarian surface epithelium and fallopian tube. Am J Pathol 148:47-53

17. Knight PG, Glister C (2006) TGF- $\beta$ superfamily members and ovarian follicle development. Reproduction 132(2):191-206. https://doi.org/10. 1530/rep.1.01074

18. Blumenfeld Z (2004) Ovarian cryopreservation versus ovarian suppression by $\mathrm{GnRH}$ analogues: Primum non nocere. Human Reprod 19(8):19241925. https://doi.org/10.1093/humrep/deh327

19. Gründker C, Emons G (2017) The role of gonadotropin-releasing hormone in cancer cell proliferation and metastasis. Front Endocrinol 8. https://doi.org/10.3389/fendo.2017.00187

20. Tilly JL (2001) Commuting the death sentence: how oocytes strive to survive. Nat Rev Mole Cell Biol 2(11):838-848. https://doi.org/10.1038/ 35099086

21. Perez Gl, Knudson CM, Leykin L, Korsmeyer SJ, Tilly JL (1997) Apoptosisassociated signaling pathways are required for chemotherapy-mediated female germ cell destruction. Nat Med 3(11):1228-1232. https://doi.org/ 10.1038/nm1197-1228

22. Mastro LD, Boni L, Michelotti A, Gamucci T, Olmeo N, Gori S et al (2011) Effect of the Gonadotropin-releasing hormone analogue triptorelin on the occurrence of chemotherapy-induced early menopause in premenopausal women with breast cancer. Jama 306(3). https://doi.org/10.1001/ jama.2011.991

23. Moore HC, Unger JM, Phillips KA, Boyle F, Hitre E, Porter D et al (2015) POEMS/S0230, I. N. In: Goserelin for ovarian protection during breastcancer adjuvant chemotherapy

24. Munster PN, Moore AP, Ismail-Khan R, Cox CE, Lacevic M, Gross-King M et al (2012) Randomized trial using gonadotropin-releasing hormone agonist triptorelin for the preservation of ovarian function during (neo) adjuvant chemotherapy for breast cancer. J Clin Oncol 30(5):533-538. https://doi.org/10.1200/jco.2011.34.6890

25. Leonard RCF, Adamson DJA, Bertelli G, Mansi J, Yellowlees A, Dunlop J, Thomas GA, Coleman RE, Anderson RA (2017) Anglo celtic collaborative oncology group and national cancer research institute trialists. $\mathrm{GnRH}$ 
agonist for protection against ovarian toxicity during chemotherapy for early breast cancer: the Anglo Celtic Group OPTION trial. Ann Oncol. 28(8):1811-1816. https://doi.org/10.1093/annonc/mdx184 PMID: 28472 240

26. Lambertini M, Ceppi M, Poggio F, Peccatori FA, Azim HA, Ugolini D et al (2015) Ovarian suppression using luteinizing hormone-releasing hormone agonists during chemotherapy to preserve ovarian function and fertility of breast cancer patients: a meta-analysis of randomized studies. Annals of Oncology, Mdv374. https://doi.org/10.1093/annonc/mdv374

27. Lambertini M, Moore HCF, Leonard RCF, Loibl S, Munster P, Bruzzone M, Boni L, Unger JM, Anderson RA, Mehta K, Minton S, Poggio F, Albain KS, Adamson DJA, Gerber B, Cripps A, Bertelli G, Seiler S, Ceppi M, Partridge AH, Del Mastro L (2018) Gonadotropin-releasing hormone agonists during chemotherapy for preservation of ovarian function and fertility in premenopausal patients with early breast cancer: a systematic review and meta-analysis of individual patient-level data. J Clin Oncol 36(19):19811990. https://doi.org/10.1200/JCO.2018.78.0858 Epub 2018 May 2. PMID: 29718793; PMCID: PMC6804855

28. Lambertini M, Boni L, Michelotti A et al (2015) Ovarian suppression with triptorelin during adjuvant breast cancer chemotherapy and long-term ovarian function, pregnancies, and disease-free survival: a randomized clinical trial. JAMA. 314(24):2632-2640. https://doi.org/10.1001/jama. 2015.17291

29. Salama M, Anazodo A, Woodruff TK (2019) Preserving fertility in female patients with hematological malignancies: a multidisciplinary oncofertility approach. Ann Oncol. 30(11):1760-1775. 31418765. https://doi.org/10. 1093/annonc/mdz284

30. Falorio S, Angrilli F, Fioritoni G (2008) Gonadotropin-releasing hormone analog treatment for the prevention of treatment-related ovarian failure and infertility in women of reproductive age with Hodgkin lymphoma. Leuk Lymphoma. 49(6):1087-1093. 18452079. https://doi.org/10.1080/ 10428190802035982

31. Driul L, Londero AP, Papadakis C, Candoni A, Bertozzi S, Fanin R, Marchesoni D (2012) Fertility in women survivors of hematological malignancies: what is the real role of GnRH analogue treatment? Clin Exp Obstet Gynecol. 39(4):504-508 PMID: 23444754

32. Blumenfeld Z, Zur H, Dann EJ (2015) Gonadotropin-releasing hormone agonist cotreatment during chemotherapy may increase pregnancy rate in survivors. Oncologist 20(11):1283-1289. https://doi.org/10.1634/ theoncologist.2015-0223 Epub 2015 Oct 13. PMID: 26463871; PMCID: PMC4718431

33. Blumenfeld Z, Avivi I, Eckman A, Epelbaum R, Rowe JM, Dann EJ (2008) Gonadotropin-releasing hormone agonist decreases chemotherapyinduced gonadotoxicity and premature ovarian failure in young female patients with Hodgkin lymphoma. Fertil Steril. 89(1):166-173. https://doi. org/10.1016/j.fertnstert.2007.02.010 Epub 2007 Jun 28. PMID: 17601603

34. Blumenfeld Z, Patel B, Leiba R, Zuckerman T (2012) Gonadotropin-releasing hormone agonist may minimize premature ovarian failure in young women undergoing autologous stem cell transplantation. Fertil Steril 98(5):1266-70.e1. https://doi.org/10.1016/j.fertnstert.2012.07.1144 Epub 2012 Aug 27. PMID: 22935556

35. Demeestere I, Brice P, Peccatori FA, Kentos A, Dupuis J, Zachee P et al (2016) No evidence for the benefit of gonadotropin-releasing hormone agonist in preserving ovarian function and fertility in lymphoma survivors treated with chemotherapy: final long-term report of a prospective randomized trial. J Clin Oncol 34(22):2568-2574. https://doi.org/10.1200/ jco.2015.65.8864

36. Pagani, O., Regan, M. M., Walley, B. A., Fleming, G. F., Colleoni, M., Láng, I., International, G. R. ..... (2014). Adjuvant exemestane with ovarian suppression in premenopausal breast cancer. Retrieved from https://www. ncbi.nlm.nih.gov/pubmed/24881463

\section{Publisher's Note}

Springer Nature remains neutral with regard to jurisdictional claims in published maps and institutional affiliations.

\section{Submit your manuscript to a SpringerOpen ${ }^{\circ}$ journal and benefit from:}

- Convenient online submission

- Rigorous peer review

- Open access: articles freely available online

- High visibility within the field

- Retaining the copyright to your article

Submit your next manuscript at $\boldsymbol{\nabla}$ springeropen.com 